\title{
CONTROLLING MOISTURE LOSS AS A TOOL TO REDUCE BRUISE SUSCEPTIBILITY
}

\author{
Verstreken E., García J.L. *, Ruiz-Altisent M.^, De Baerdemaeker J. \\ Department of Agroengineering and -Economics \\ Katholieke Universiteit Leuven \\ K. Mercierlaan 92 \\ B-3001 Heverlee \\ Belgium \\ * Departamento de Ingenieria Rural \\ Universidad Politecnica de Madrid \\ 28040 Madrid \\ Spain
}

\begin{abstract}
A method to reduce the bruise susceptibility of apples by controlling the moisture loss of the fruit was evaluated. Previous research indicates that reduction of the relative humidity of the storage air leads to an immediate effect on the weight loss and on skin properties and to a lower bruise susceptibility of apples. The diffusion equation is used to determine the waterpotential profile inside the fruit during storage. Characteristics of the waterpotential distribution in the fruit are related to measured bruise volumes. The results indicate how this model can be used to control bruise susceptibility.
\end{abstract}

Keywords: damage, susceptibility, permeability, finite element method, simulation, quality control

\section{INTRODUCTION}

Literature and practice indicate that a certain amount of moisture loss is required to reduce the bruise susceptibility of fruits during handling. However the weight loss during storage should be kept as low as possible to avoid shriveling of the fruit and to avoid loss of product weight.

Mechanical damage of fruits is mainly caused by impact forces during harvest, handling and transport (Garcia, et al., 1988), so the sensitivity of apples to damage by impact is emphasized in this work. Different factors which could influence the bruise susceptibility of apples are described by Johnson and Dover (1990). These factors are the rate of ripening, the mineral content, the harvest date and ripeness stage, the mechanical properties of the flesh and of the skin.
Bruise volumes appeared to be negatively correlated with the percentage of weight loss during storage (Johnson and Dover, 1990). This phenomenon is also described by other researchers (Garcia, et al., 1994; Horsfield, et al., 1972), who state that the turgidity of the surface tissue (internal cellular stress) of fnuits is affected by the relative humidity of the surrounding air.

The weight loss of fruits during storage mainly consists of the transpiration of water. The rate of transpiration is determined by the humidity and temperature of the air, the air circulation, stacking of the boxes and the ripeness stage of the fruit. This was also found in the (unpublished) experimental results obtained in 1994 in the framework of the ECCAMAR project. McCarthy and Perez (1991) described the process of water loss of a drying apple slab with the diffusion equation of Fick and derived a diffusion coefficient for the flesh. Since the driving 
force for water transport is a difference in waterpotential, the distribution of waterpotential in the fruit will be simulated with the diffusion model in this work.

It is clear that an interaction exists between storage conditions, weight loss, ripeness stage, mechanical properties and bruise susceptibility. Reduction of the bruise susceptibility by controlled dehydration seems to be a promising application (Horsfield, et al., 1972; Johnson and Dover, 1990), but the models required for prediction are not yet available.

In this report an approach for this problem is proposed. Simulations of the waterpotential distribution inside the fruit during storage under different conditions are related to bruise volumes.

\section{MATERIALS AND METHODS}

\subsection{Experimental setup}

Apples. A batch of 130 freshly harvested Delbare Estival apples was kept in storage for up to 12 days. The batch consisted of apples of 2 different harvest dates (10/08/94 and 17/08/94).

A similar experiment was conducted with 110 Golden Delicious apples.

Storage conditions. One group of Delbare Estival apples was kept at $2^{\circ} \mathrm{C}$ and $50 \% \mathrm{RH}$ and another group in perforated plastic bags to obtain $\pm 95 \% \mathrm{RH}$. One batch of Golden Delicious apples was kept at $20^{\circ} \mathrm{C}$ and $40 \% \mathrm{RH}$, while the other batch was kept at $\pm 95 \% \mathrm{RH}$ in perforated plastic bags.

After different storage periods, 10 apples of each group were removed from storage in both experiments and the weight loss, mechanical properties of flesh and skin and bruise susceptibility were determined

Mechanical properties of flesh and skin. The firmness of the fruit flesh (FF) was determined with a handhold penetrometer. The skin property measured was a modulus of elasticity determined from the maximum force/maximum deformation (SF/D) recorded at perforation of the skin with a $0.48 \mathrm{~mm}$ diameter pin.

Bruise volume measurements. A $52.1 \mathrm{~g}$ mass was dropped on the fruit from a constant height of $8 \mathrm{~cm}$. The contact radius of the spherical head of the mass was $2 \mathrm{~cm}$. After a couple of hours $(2$ to 4$)$ the bruise depth $B$ and diameter $D$ were measured and the bruise volume BV was calculated (Chen and Sun, 1981) :

$$
\mathrm{BV}=\frac{\pi \mathrm{D}^{2} \mathrm{~B}}{6}
$$

Statistical analysis of the experimental results. An analysis of variance (SAS, SAS Institute Inc.) was conducted to evaluate the effect of storage time and relative humidity of the storage air on the evolution of the bruise susceptibility. A correlation analysis was performed on the whole experimental dataset to find interesting relationships.

\subsection{Simulation of the water distribution}

The driving force for water transport is not the difference in water concentration, but it is basically the difference between the waterpotential inside the apple and the waterpotential of the surrounding air. Compared with the heat transport : the diffusion of heat is caused by a difference in temperature (Luikov, 1966). The diffusion of water is caused by a difference in waterpotential and the water will flow from a higher to a lower potential (cf. electric current). This phenomena can be described with a diffusion equation, expressed in terms of waterpotentials (Luikov, 1966) :

$$
\frac{\partial \psi_{w}}{\partial t}=D_{p} \frac{\partial^{2} \psi_{w}}{\partial x^{2}}
$$

with $\quad \psi_{w}:$ waterpotential in apple

$\mathrm{D}_{\mathrm{p}}$ : diffusion coefficient of waterpotential

The diffusion equation, used to describe the water transport in the fruit, is a partial differential equation. This is not easily solved for complex geometries. A numerical method like the finite element method can be used for this purpose. It is applied in this work with the software package ANSYS (Swanson Analysis Systems, Inc.). Solutions are obtained at discrete values of time and position in the object. A model of the object is entered by a series of interconnected elements and nodes. The geometry used in this work was a slice ( $1.5 \mathrm{~cm}$ thickness) taken from the equator part of the apple (fig. 7). This was done to reduce the number of nodes. The presence of a very thin $(0.2 \mathrm{~mm})$ but highly impermeable skin causes very high gradients near the apple surface. According to the objectives of this work, the highest interest is in the gradients near the surface. So a very fine mesh was required near the surface. The material properties are : the diffusivities of flesh and skin, $5.55 .10^{-11}$ and $5.55 .10^{-15} \mathrm{~m}^{2} / \mathrm{s}$ respectively (Van Woensel, 1980). The initial condition is a uniformly distributed waterpotential in the fruit $(-1.3 \mathrm{MPa}$, Van Woensel, 1980). The boundary condition is convective transport out of the object. The 
waterpotential of the air depends on the temperature and relative humidity and can be calculated from :

$$
\psi_{\text {wa }}=\frac{\mathrm{RT}}{\overline{\mathrm{V}}_{\mathrm{w}}} \ln \frac{\mathrm{RH}}{100}
$$

The convection coefficient is calculated from dimensionless parameters correlated with experimental data for flow over a single sphere (Bejan, 1993) :

$$
\begin{aligned}
& \mathrm{Sh}=0.3+\frac{0.62 \mathrm{Re}^{1 / 2} S c^{1 / 3}}{\left(1+(0.4 / \mathrm{Sc})^{2 / 3}\right)^{1 / 4}}\left[1+\left(\frac{\mathrm{Re}}{282000}\right)^{5 / 8}\right]^{4 / 5} \\
& \mathrm{Sh}=\frac{\overline{\mathrm{h}_{\mathrm{m}}} \mathrm{L}}{\mathrm{D}_{\mathrm{wa}}} ; \mathrm{Re}=\frac{\mathrm{vL}}{v} ; \mathrm{Sc}=\frac{v}{\mathrm{D}_{\mathrm{wa}}}
\end{aligned}
$$

\section{for $\operatorname{ReS}>0$.}

After simulating different storage periods under the imposed boundary conditions, the waterpotential distribution inside the fruit is obtained. Different characteristics of this profile are related to the measured bruise volumes.

The influence of the presence of the -very impermeable- apple skin on the profile of the waterpotential was investigated. This was done by giving the skin the same diffusivity as the flesh, thereby neglecting the presence of a skin.

The flesh and skin diffusivity were decreased with 25 $\%$, which may occur in practice for apples of an earlier harvest date (smaller cells with thicker walls, more cell to cell contact due to less intercellular air spaces), in order to see the effect on the distribution of the waterpotential in the fruit.

\section{RESULTS}

\subsection{Experimental results}

Delbare Estival apples. The experimental results are shown in fig. 1 and 2, and tables 1 and 2. The data and the analysis of variance show that weight loss is instantaneously influenced by the relative humidity of the storage air (table 1 and 2). The bruise volumes for both harvest dates are higher after storage at $95 \%$ $\mathrm{RH}$ than at $50 \% \mathrm{RH}$, but the difference is not significant in the experimental data. There is a trend for a decreasing bruise volume after longer storage. This trend is significant at $50 \% \mathrm{RH}$, but not significant at $95 \%$. The bruise volume was significantly higher for the later harvest date than for earlier harvest date. Flesh firmness was not affected by storage at different relative humidities for both haryest dates. The modulus of elasticity of the skin showed a more significant decrease at the lower humidity of the storage air. This is so for both harvest dates.

Golden Delicious apples. The experimental results are shown in fig. 3 and table 3 . The same conclusions as for Delbare Estival apples can be made. Storage at different relative humidities had a significant effect on weight loss, modulus of elasticity of the skin and also bruise volume. No significant effect on the flesh firmness was observed.

The correlation analysis on the whole dataset indicates no significant correlation between bruise volume and flesh firmness, but bruise volume is significantly and strongly correlated with skin modulus of elasticity, weight loss (negative correlation) and mostly with the ratio skin modulus of elasticity/flesh firmness. A faster decrease in the modulus of elasticity of the skin compared to the decrease in flesh firmness (through storage in a dryer atmosphere) results in a faster decrease of the bruise volume. Apples of a later harvest date with a lower flesh firmness show higher bruise volumes. This confirms the results of Johnson and Dover (1990).

\subsection{Simulation results}

It was observed that in almost all cases the waterpotential gradient occurred within the apple skin (fig. 8). From fig. 4 and fig. 5 (for storage conditions in the Golden Delicious experiment) it can be seen that during the first few days a gradient is formed across the skin. During further storage the internal waterpotential will gradually (but very slowly) decrease. The same observations could be made for the conditions of the experiment with Delbare Estival apples.

The following parameters were extracted from the waterpotential profile :

- the waterpotential at the fruit surface $\left(\psi_{s}\right)$

- the waterpotential in the center of the skin $\left(\psi_{1 c}\right)$

- the waterpotential just beneath the skin $\left(\psi_{b s}\right)$

- the waterpotential in the center of the fruit $\left(\psi_{c}\right)$

- the sum of the waterpotential values of all elements (sum( $(\Psi))$

- the sum of the waterpotential gradients of all elements $(\operatorname{sum}(\Delta \psi))$

From fig. 6 it is clear that the waterpotential just beneath the skin decreases fastest for the lower relative humidity. This decrease in waterpotential may be due to a lower turgor pressure in the superficial cell layers. This may also be the explanation for the observed faster decrease in bruise volume at the lower relative humidity of the storage 
air.In table 4 the correlations between these profile parameters and the experimentally determined bruise volumes are given. It should be mentioned that all the simulations were performed with the same values of skin and flesh diffusivity and for an initial homogeneous waterpotential. These results were compared with bruise volumes in apples of different variety and ripeness. One could expect different values of diffusivities for these fruits. Knowledge about the evolution of these values during ripening and the relationship with other measures of texture is necessary for further use of this model.

Neglecting the presence of a skin in a simulation, resulted in waterpotential profiles like fig. 9, where the gradient is spread out over a large part of the fruit flesh. It is clear that the skin is the limiting factor in the diffusion of water and that it is therefor essential to have a good idea of the evolution of the skin thickness and diffusivity during ripening.

The change in waterpotential values after decreasing the flesh and skin diffusivities with $25 \%$ was higher for the more internal parts in the fruit and for the longer storage periods. The correlation coefficients were therefor best for these parameters (table 5). For the other parameters the correlation coefficients did not change compared to these obtained with the original data.

\section{CONCLUSIONS}

The measurement results on bruise volumes and storage conditions yield the following conclusions :

- Storage at different relative humidities of the storage air instantaneously resulted in significantly different weight losses and gradually in significantly different bruise volumes and elastic properties of the skin. Flesh firmness was not affected by the difference in relative humidity for the storage periods studied.

- Bruise susceptibility seemed to decrease during storage. An explanation for this behavior could be the decrease in modulus of elasticity of skin and flesh during ripening and also the cell wall degradation. This decrease in bruise susceptibility occurs faster at a lower relative humidity, probably caused by the faster decrease in modulus of elasticity of the skin. A lower relative humidity causes an increased water transpiration, which results in a lower turgidity of the superficial cell layers of the fruit and probably also in a lower modulus of elasticity of the skin.

- Bruise susceptibility was higher for the later harvest date, which can be explained by the larger cells and thinner cell walls which occur in apples of a later harvest date (Johnson and Dover, 1990).
It is possible to simulate the waterpotent distribution inside a fruit during storage under knor conditions of temperature and relative humidity $w$ a diffusion model. Parameters related to the char in waterpotential near the skin (waterpotential at 1 surface of, in or just beneath the skin) or paramet related to a global change in the waterpotent distribution (sum of waterpotential values gradients of all elements) seem to be best correla with the experimentally measured bruise volumes. is however necessary to have a good estimate of value of flesh and skin diffusivities, of the st thickness, and how these are influenced by ripeness stage. These parameters have a signific: influence on the waterpotential profile. Especia the skin characteristics seem to be important, as v also observed in the experiments.

This research indicates the possibility to model waterpotential distribution in fruit in order to givi prediction of the optimal storage conditions to red: the bruise susceptibility. Information is required the values of the skin and flesh diffusivities and $s$ thickness and how they are influenced by the ripen stage, variety etc.

The next steps of the research will include :

- sensitivity analysis of the diffusion model determine which parameters should be measured a with which accuracy.

- relationship between waterpotential and w: concentration so that water concentration profiles , be obtained from the simulated waterpotential prof: and the weight loss can be calculated.

- experimental measurements of the requi parameters and their change with ripeness stage. - a control strategy to minimize bruise susceptibilit.

\section{LIST OF SYMBOLS}

$D_{w a} \quad$ : diffusion coefficient of water in air

$\overline{\mathrm{h}_{\mathrm{m}}} \quad$ : average mass transfer coefficient

L : diameter of sphere

R : gasconstant

Re : Reynolds number

RH : air relative humidity

Sc : Schmidt number

Sh : Sherwood number

T : air temperature

v : air velocity

$\overline{\mathrm{V}}_{\mathrm{w}} \quad$ : partial molar volume of the air

$\psi_{w} \quad$ : waterpotential in apple

$\psi_{\text {we }} \quad$ : waterpotential of the air

$v \quad$ : kinematic viscosity 


\section{REFERENCES}

Bejan, A. (1993). Heat transfer, Chap. 5. John Wiley \& Sons, Inc., Singapore.

Chen, P.and Z. Sun (1981). Impact parameters related to postharvest bruising of apples. ASAE paper no. 81-3041.

García, C., M. Ruiz and P. Chen (1988). Impact parameters related to bruising in selected fruits. ASAE paper no. 88-6027.

García, J.L., M. Ruiz-Altizent and P. Barreiro (1994). Factors influencing apple and pear physical properties and bruise susceptibility. Report no. 94-G-062, presented at the AgEng meeting in Milano, Italy.

Horsfield, B.C., R.B. Fridley and L.L. Claypool (1972). Application of theory and elasticity to the design of fruit harvesting and handling equipment for minimum bruising. Trans. of the $A S A E$, 15(4), 746-750.

Johnson, D.S. and C.J. Dover (1990). Factors influencing the bruise susceptibility of Bramley's seeding apples. Seminoario Internacional sobre Danos por impacto en frutas y hortilizas, FIMA 90, Zaragoza, Spain.

Luikov, A.V. (1966). Heat and mass transfer in capillary porous bodies, Chap. 6. Pergamon Press, New York.

McCarthy, M.J. and E. Perez (1991). Model for transient moisture profiles of a drying apple slab using the data obtained with magnetic resonance imaging. Biotechnol. Prog., 7, 540-543.

Van Woensel, G. (1980). Waterpotentiaal veranderingen en mechanische eigenschappen van appels. Licentiaatsverhandeling K.U.-Leuven.

\section{TABLES AND FIGURES}

Table 1. Delbare Estival apples harvested 10/08/94. Mean values (*) of weight loss (\%), bruise volume $\left(\mathrm{mm}^{3}\right)$, flesh firmness $(\mathrm{N})$ and skin modulus of elasticity (N/mm) after different periods of storage.

\section{Storage at $50 \%$ RH}

\begin{tabular}{llllllllll}
\hline days & & loss & & BV & & FF & & & SF/D \\
\hdashline 0 & 0 & A & 170 & A & 60.4 & A & 5.5 & A \\
5 & & 0.55 & B & 163 & A & 57.2 & A & 5.1 & AB \\
8 & & 0.89 & C & 161 & A & 56.5 & A & 5.2 & B \\
12 & 2.16 & D & 137 & B & 59.5 & A & 4.6 & C \\
\hline
\end{tabular}

\section{Storage at $95 \%$ RH}

\begin{tabular}{lllllllllll}
\hline days & loss & & BV & & FF & & & SF/D \\
\hdashline 0 & 0 & A & 170 & A & 60.4 & A & 5.5 & A \\
5 & 0.27 & B & 165 & AB & 57.8 & A & 5.7 & AB \\
8 & & 0.39 & C & 159 & AB & 56.6 & A & 5.8 & AB \\
12 & 0.57 & D & 147 & B & 56 & A & 5.3 & B \\
\hline
\end{tabular}

-Table 2. Delbare Estival apples harvested 17/08/94. Mean values $(*)$ of weight loss $(\%)$, bruise volume $\left(\mathrm{mm}^{3}\right)$. flesh firmness $(\mathrm{N})$ and skin modulus of elasticity $(\mathrm{N} / \mathrm{mm})$ after different periods of storage.

\section{Storage at $50 \%$ RH}

\begin{tabular}{llllllllll}
\hline days & loss & & BV & & FF & & \multicolumn{1}{l}{ SF/D } \\
\hline 0 & 0.00 & A & 195 & A & 51.5 & A & 5.7 & A \\
2 & 0.39 & B & 174 & AB & 48.4 & A & 5.2 & B \\
5 & 1.49 & C & 168 & CB & 51.0 & A & 5.1 & B \\
7 & 1.94 & D & 151 & C & 52.6 & A & 4.6 & C \\
\hline
\end{tabular}

\section{Storage at $95 \%$ RH}

\begin{tabular}{|c|c|c|c|c|c|c|}
\hline days & loss & & BV & & FF & $\mathrm{SF} / \mathrm{D}$ \\
\hline 0 & 0.00 & A & 195 & A & $51.5 \mathrm{~A}$ & $5.7 \mathrm{~A}$ \\
\hline 2 & 0.10 & B & 184 & A & $47.5 \mathrm{~A}$ & $5.7 \mathrm{~A}$ \\
\hline 5 & 0.22 & C & 178 & A & $47.7 \mathrm{~A}$ & $5.4 \mathrm{AB}$ \\
\hline 7 & 0.38 & D & 173 & A & $49.9 \mathrm{~A}$ & $5.0 \quad \mathrm{~B}$ \\
\hline
\end{tabular}

Table 3. Golden Delicious apples.

Mean values (*) of weight loss (\%) and bruise volume $\left(\mathrm{mm}^{3}\right)$ after different periods of storage.

\begin{tabular}{|c|c|c|c|c|}
\hline & \multicolumn{2}{|c|}{$40 \% \mathbf{R H}$} & \multicolumn{2}{|c|}{$95 \% \mathbf{R H}$} \\
\hline days & loss & BV & loss & BV \\
\hline 0 & 0.00 & $153.7 \mathrm{~A}$ & 0.00 & $153.7 \mathrm{~A}$ \\
\hline 0.3 & 0.54 & $147.2 \mathrm{AB}$ & 0.02 & $152.4 \mathrm{~A}$ \\
\hline 1 & 0.62 & $133.4 \mathrm{ABC}$ & 0.06 & $162.1 \mathrm{~A}$ \\
\hline 4 & 2.05 & $132.7 \mathrm{ABC}$ & 0.70 & $154.6 \mathrm{~A}$ \\
\hline 5 & 2.40 & $121.4 \quad B C$ & 0.65 & $159.6 \mathrm{~A}$ \\
\hline 8 & 3.89 & 110.5 & 1.53 & $142.0 \mathrm{~A}$ \\
\hline
\end{tabular}

(*) Mean values with the same letter are not significantly different.

Table 4. Correlation analysis : simulated profile parameters versus measured bruise volumes.

\begin{tabular}{llll}
\hline & BV & & BV \\
\hline$\psi_{s}$ & 0.58 & $\psi_{c}$ & 0.49 \\
$\psi_{c c}$ & 0.56 & $\operatorname{sum}(\psi)$ & 0.6 \\
$\psi_{b 3}$ & 0.58 & $\operatorname{sum}(\Delta \psi)$ & -0.58 \\
\hline
\end{tabular}

Table 5. Correlation analysis : adapted simulated profile parameters versus measured bruise volumes.

\begin{tabular}{llll}
\hline & BV & & BV \\
\hdashline$\psi_{s}$ & 0.58 & $\Psi_{c}$ & 0.58 \\
$\psi_{x c}$ & 0.57 & $\operatorname{sum}(\psi)$ & 0.6 \\
$\psi_{b}$ & 0.61 & $\operatorname{sum}(\Delta \psi)$ & -0.58 \\
\hline
\end{tabular}



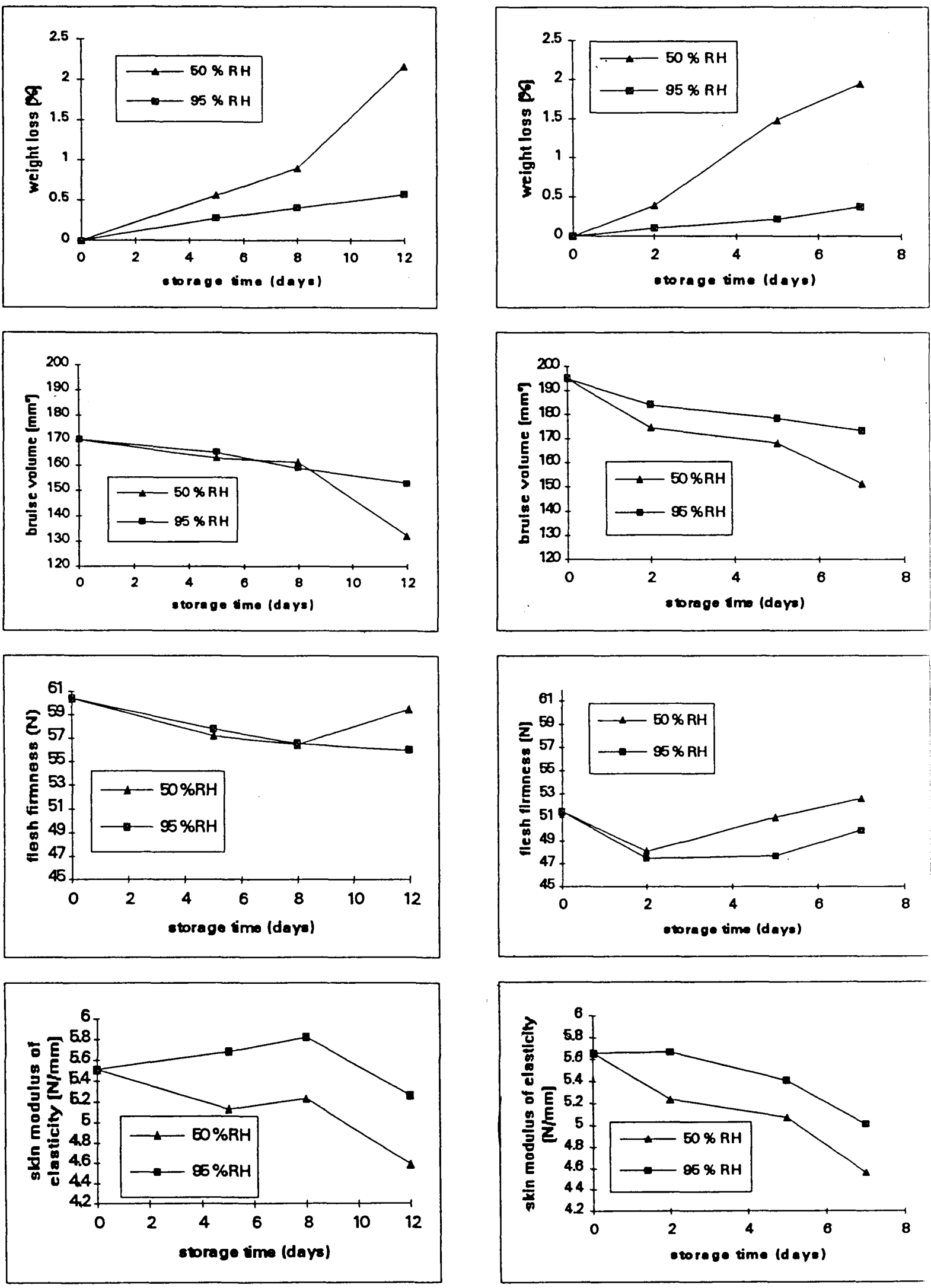

Fig. 1.a-d : results for Delbare Estival apples harvested 10/08/94 ( $\left.{ }^{\circ}\right)$

( $\left.{ }^{\circ}\right)$ a : weight loss (as $\%$ of original weight) after different periods of storage b : bruise volume $\left(\mathrm{mm}^{3}\right)$ after different periods of storage

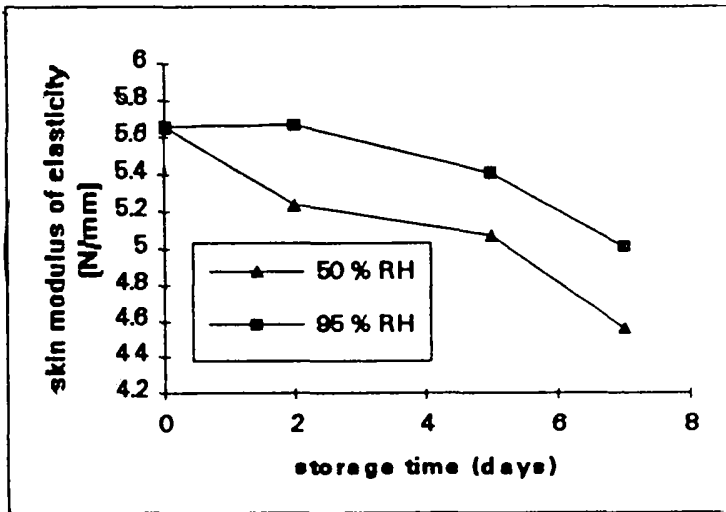

Fig. 2.a-d : results for Delbare Estival apples harvested 17/08/94 $\left(^{\circ}\right)$

( $\left.{ }^{\circ}\right)$ c : flesh firmness (N) after different periods of storage

d : skin modulus of elasticity $(\mathrm{N} / \mathrm{mm})$ after different periods of storage 

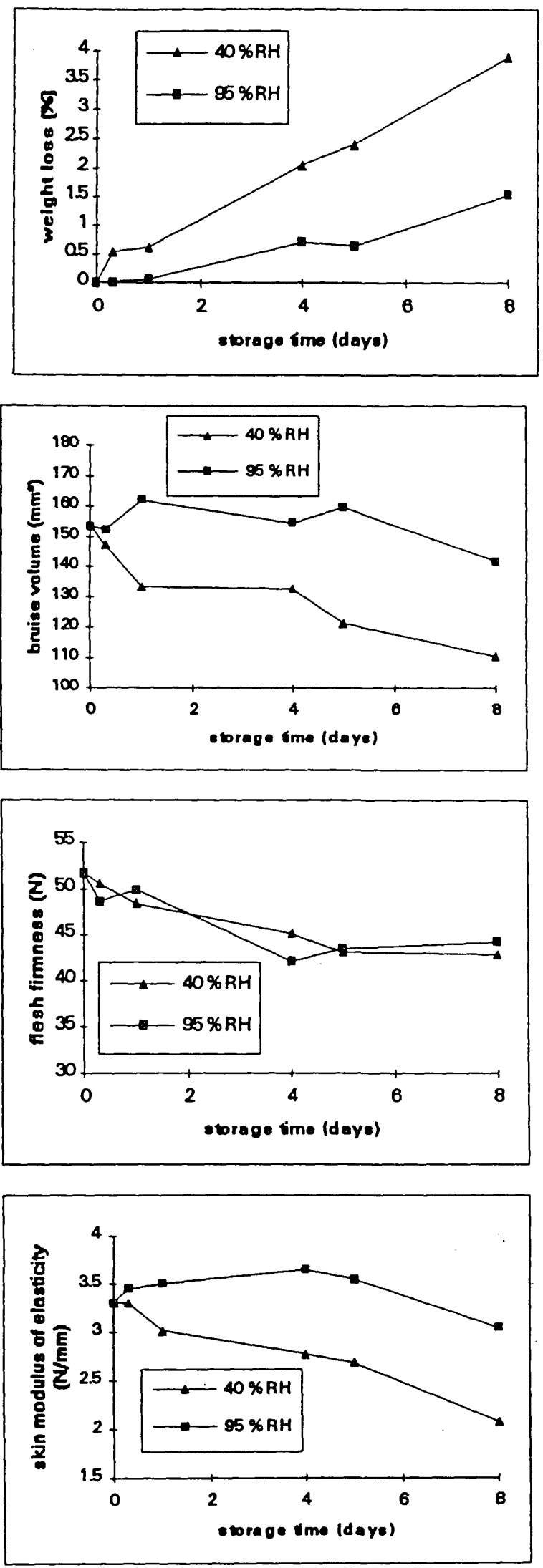

Fig. 3.a-d : results for Golden Delicious apples ( ${ }^{\circ}$ )

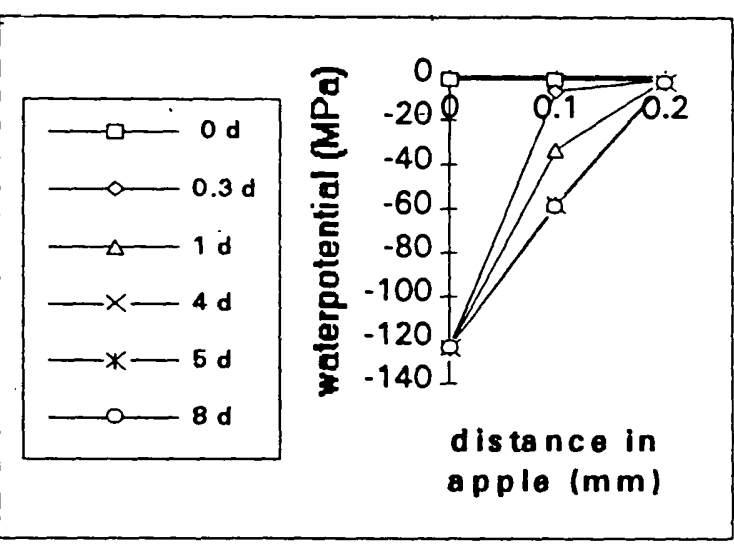

Fig. 4 : Evolution of profile of waterpotential in the apple skin during storage in $40 \% \mathrm{RH}(-124 \mathrm{MPa})$

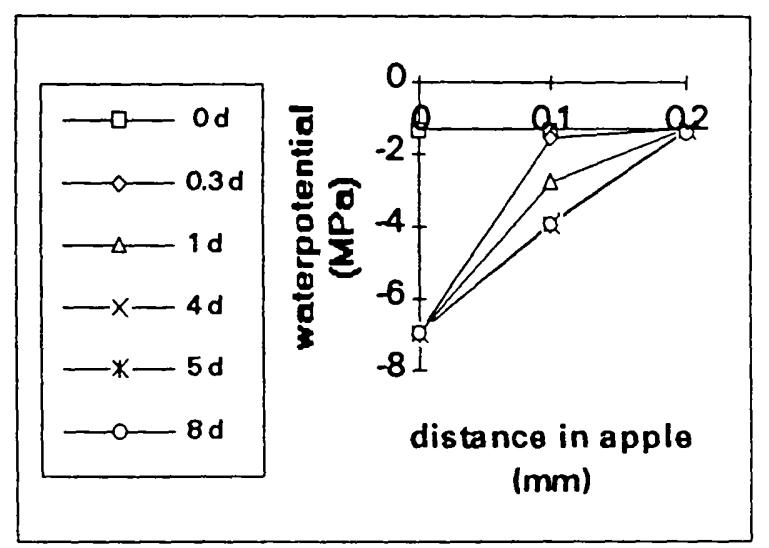

Fig. 5 : Evolution of profile of waterpotential in the apple skin during storage at $95 \% \mathrm{RH}(-6.9 \mathrm{MPa})$

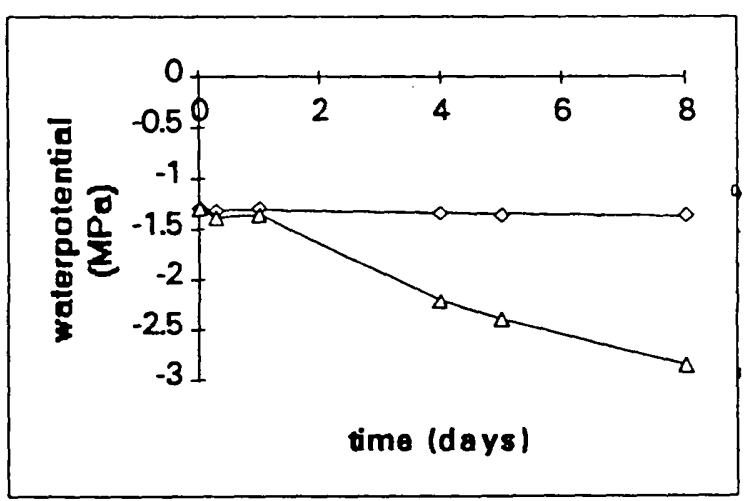

Fig. 6 : Evolution of the waterpotential just beneath the skin during storage at $40(\Delta)$ and $95(0) \% \mathrm{RH}$ for Golden Delicious apples 


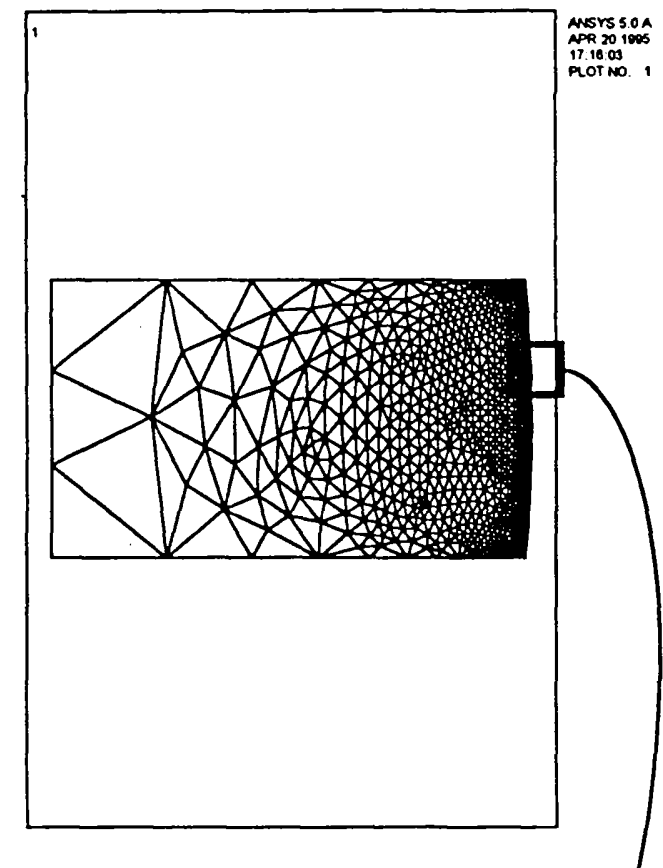

Fig. 7 : Geometry and mesh of the model of an apple slab, used for the simulations

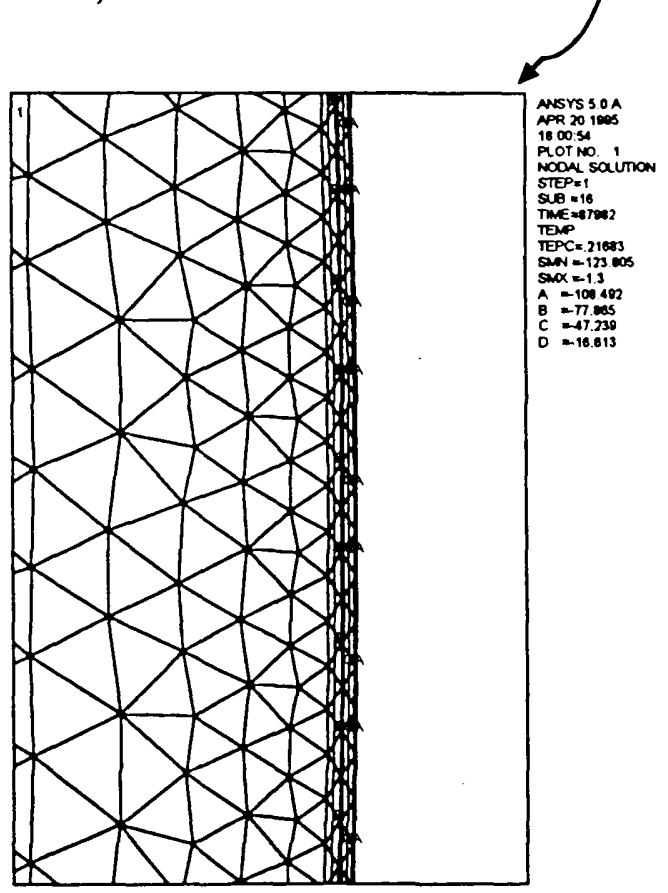

Fig. 8 : Simulation results for 1 day of storage at 40 $\% \mathrm{RH}(-124 \mathrm{MPa})$ : zoom on the skin to view the contour display

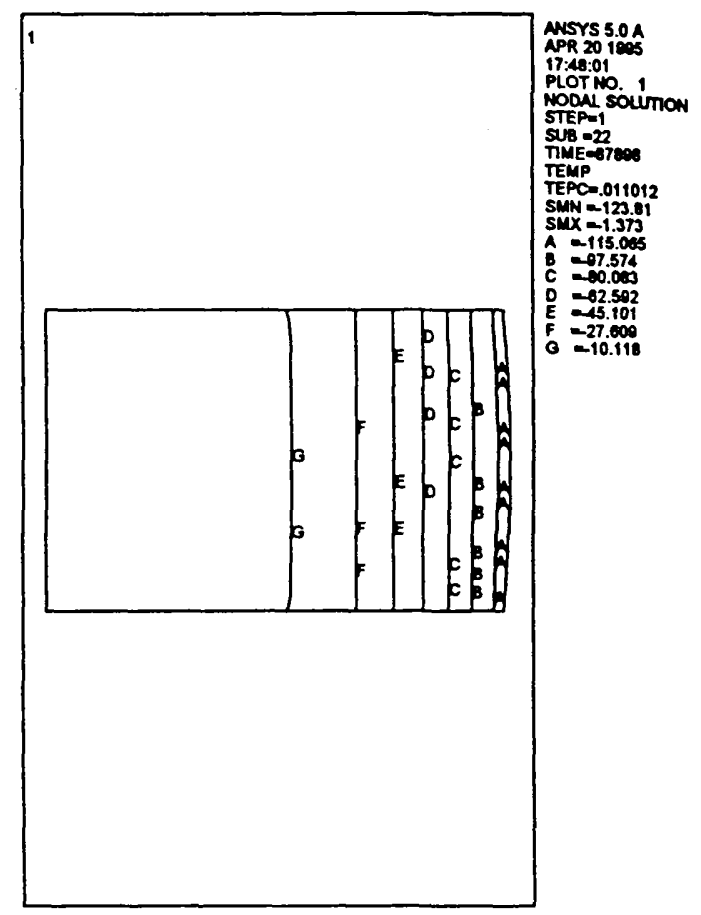

Fig. 9 : Simulation results for 1 day of storage at 40 $\% \mathrm{RH}(-124 \mathrm{MPa})$ : simulation without the presence of a skin 